\title{
ELEMENTS IN FATHEY \\ GHANEM'S THE MAN WHO LOST HIS SHADOW
}

\author{
A Research submitted by \\ Alyaa Mohamed El Sayed Radwaan \\ Assistant Lecturer of English Language - Nile Academy \\ for Science
}




\section{Abstract}

This study aims at investigating and analyzing the contextual element in Fathey Ghanem's The Man Who Lost His Shadow. The researches has recommended a model of analysis that involves the basic contextual aspects that underline the novel at hand. These are: Discourse Markers, and Deixis (Temporal and Spatial). Such analysis leads to highlighting these prominent aspects and realizing its role and effect in conveying the message determined by the novelist.

Key Words: Ghanem, Stylistics, Context, Deixis, and Discourse Markers .

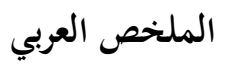

تمدف هذه الدراسة الي بحث و تحليل عناصر السياق في رواية فتحي غانم "الرجل الذي

فقد ظله". وقد اقترحت الباحثة نموذج تحليلي و الذي يشتمل علي العناصر الاساسية للسياق والموجودة في الرواية موضع الدراسة. و تشتمل تلك العناصر علي الادوات الرابطة للجمل الحوارية

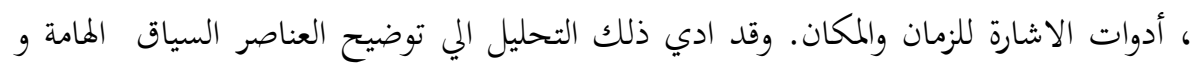

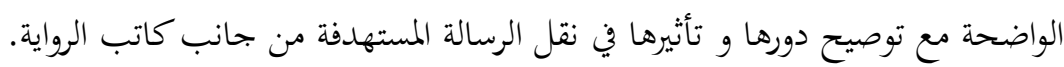

الكلمات الهامة: فتحي غانم، الأسلوبيات، الحوار، الأدوات الرابطة للجمل الحوارية، أدوات الاشارة للزمان والمكان

\section{Introduction}

Throughout linguistic studies, context can be categorized into: linguistic, cognitive and social. It is clear that cohesion and coherence are vital elements in the study of text and 
discourse. Thus, it is essential in the study of discourse analysis to highlight or underline the context in which discourse occurs.

The relationship between discourse and context is studied by Cook (1999 as cited in Song, 2010 ) who refers to the term context as

can be used in a broad and narrow sense. In the narrow sense, it refers to (knowledge of factors outside the text under consideration. In the broad sense, it refers to (knowledge of these factors and to (knowledge of other parts of the text under consideration, sometimes referred to as "co-text." (P.24).

Context can be categorized into three main categories: linguistic context, situational context and cultural context. Linguistic Context means the context within discourse that is outlined by words, phrases and sentences. The three main aspects that are involved in linguistic context are: deictic, cotext and collocation.

Situational Context is generally referred to as the time, place and environment in which the discourse occur in addition to the participants' relationship. Cultural Context is determined by culture or background of language community in which the speakers communicate such as social role, social status, sex and age share altogether in influencing language. 


\section{Biography of Fathey Ghanem}

Being a natural narrator, Fathey Ghanem dedicates a great part of his life in mastering the art of fiction. Despite his preoccupation with journalism, Ghanem never forgot novel, which represent for his a refugee to which he resorted in grief and happiness. He used story telling as a way to explore essential issues, which concern him whether by asking new questions or evaluating the past.. Ghanem indicates that "I am one of minority writers who seldomly use the word " I" and I am not among those who talk highly about themselves" ( as cited in EL Sabagh, 1995, P. 438) (my own translation).

Concerning the talent of Ghanem in writing ,Farouk Abdel Qader (1999) regards Ghanem as

one of the greatest talent in the field of novel all over the Arab Countries. He is a novelist who writes excessively and his world of writing unveils what is going on the filed of journalism which harms him as a great novelist. .. His talent is rich compared his mates and he is , may ne, the first who dealt with the feature of religious terrorism before any body else.( $P$.18) (my own translation).

In the seminar entitled " Fathey Ghanem .. a creator who does lost his shadow" hold on 16/5/2011 at Supreme Council of Culture - cultural committee- , Youssef El 
Kaeed (2011) refers back to Ghanem as being the reason for not publishing his works. He states

Fathey Ghanem is the first responsible for not publishing his works or not having new issues from them..He does bother himself with what was written about his works whether criticism or research study. If some asks his ti give him/her a copy of his works he answer that it Is not his business. The matter become more difficult after his death as the whole mater goes to his inherits. (my own translation).

Ascending and descending the social ladder is based on actual experience. The characters in the novel are and realistic in the sense that they embody their motos and views. This is clear in the character of Youssef Abd EL Hamid who turned to be a fierce fox that pad over the skulls and skeletons of his victims to grow and develop. On the other hand, Makrouka is a poor girl who left the countryside to Cairo, and has to struggle to turn from a servant to a woman married to a primary teacher, so reach the middle class.

Concerning the title of the novel, it reflects the idea that losing the shadow is a synonym and symbol of losing one's self or self-esteem. This point is embodied through Youssef Abd El Hamid El Sewefay who 
lost his shadow within bitter struggle in order to seem or belong to or be in front of a different class other than his and to appear to have force and authority other than his which he has in reality... in order to achieve this he lost his shadow or himself... what a loss when a person losses himself and gain the whole world. (Eid. 1995. P. 54 My own translation).

\section{Data and Procedures}

\section{Context aspect:}

\section{Deixis}

For different people, deixis involve different meanings for various individuals and/or scholars. Deixis are these expressions which point to space and time and name them as deictic expressions. Later on, scholars refer to the term deixis as these cases " where the referent is located using the current speech event or one or more of its participants as reference points" (Cruse, 2000, P.319). Deixis is categorized into five main categories: person deixis, spatial deixis, temporal deixis, social deixis and discourse deixis.

Person Deixis includes three types of person: these are the first person or speaker, the second person or the addressee and the third person which includes important or essential participants in the speech situation except for speaker or hearer. 


\section{Deixis in Discourse:}

Concerning the role of deixis in discourse, it is clear that

Deixis is a linguistic operation that makes the physical and social world of the discourse participants accessible for the interpretation of the current speech event by making it part of the world discourse... The speaker uses deictic expressions in order to direct the addressee's attention to the speaker situation, or to an entity or event that is part of the speech situation, or to a constituent or property of that entity or event. (Laczko, 2012, P.290).

The selection of the numerous deictic expressions that refers to referential relationship between the discourse world or context and elements of speech event is not randomly or haphazardly. Thus, the spatial center refers to the location of the speaker within the speech event whereas the temporal center indicates the time of speech event.

Thus, via joining the physical space to the spatial relationships of discourse, it is clear that

Spatial Deixis is not simply a basic category ,it is also complex or open. As opposed to the traditional Levinsonian concept of "place Deixis", I call it "spatial Deixis" because this terminal shift has important implications with respect to the way the deictic 
elements operate in addition to the fact that social temporal and discourse internal deictic expressions are metaphorically based on spatial relationships (Laczko, 2012, P. 292).

\section{Types of Deixis}

\section{1-Temporal Deixis}

Temporal deixis indicates the time within which an utterance occurs and is shown through tense, time adverbials and temporal expressions. Three basic categories of expressions underline the time concept.

\section{Now}

The use of Now is frequent in free indirect discourse (FID) wherein it is easy to comprehend the events from the character's point of view and not the narrator. In discourse, now shows two specific properties; in the first now is an anaphor and in the other, It is an exemplification. Thus, now points to a temporal perspective point; It refers to the events of speech time or prior mentioned discourse.

Thus, now is not treated as a deictic expression, one that always makes reference to the context of utterance; but rather as perspective setting anaphor whose value is always determined by the discourse context and is constrained by the tense ... An alternative hypothesis is 
to say that in cases where now co-occurs with the pasttense, there is an operator that "shifts" now : coordinates an operator shifts the speech time coordinate to the past time., In this way, we can maintain that now is a deictic expression; it refers to the (shifted) speech time. (Altshuler, 2009, P.2 Para.2).

\section{2) Spatial Deixis}

The main concern of spatial (place) deixis is the determination of locative relative to point to aspect in the speech event. So, It is possible to refer to one element or aspect as being near to or far from the reference object. The most obvious place deictic terms are the demonstrative pronouns this and that and their plural forms these and those and the locative adverbs (locative adverbials demonstratives here and there.

\section{2- -Discourse Markers (DMs)}

As there is no agreement on the exact definition and function of discourse markers (DMs), most scholars and researchers refer to DMs as discourse connectives, discourse operators, pragmatic connectives, sentence connectives and clue phrases. Fraser (1996) indicates that

Discourse markers as a class of lexical expressions drawn primarily from the syntactic classes of conjunctions, adverbs and prepositional phrases. They 
signal a relationship between the interpretation of the segments they introduce, S2 and the prior segment, S1. They have a core meaning which is procedural, not conceptual... There are two types; those that relate the explicit interpretation conveyed by $S 2 \ldots$ and those that relate the topic of S2 to that of S1. (P.931).

There are large numbers of discourse markers, the most prominent and applicable to the novels studied are and, but and or in addition to so and because. That's why the researcher feels it essential to study these discourse markers and study their role in clarifying and comprehending both the implicit and explicit meaning and ideas intended by both writers in addition to the message(s) conveyed by these authors.

As a Connective, And is mostly used to coordinate the units and to resume the action of a speaker at the local level of idea structure. The environment in which And occur is similar to that in which But and So occur.

Similar to and, But is a discourse coordinator though the pragmatic effect is different ; as But indicates that the coming unit carries the sense of contrast. But links functional units wherein there is a contrastive relationship whether in their ideational or interactional content.

\section{Function of And}


The function of and as clause combining is to cohere one sentence to another, consequently joining a clause to its predecessor. So, and is used

when all or most of the participants, and may be used (a) when all or most of the participants change from one sentence to another ...(b) to link a series of subpoints contributing to a general argument, or $(c)$ to introduce the next item in a series of things to be said or questions to be asked. (Turk, 2004, P. 235).

\subsubsection{AND as discourse Cohesion}

Discourse cohesion has two functions, to join a series of sub joints and to introduce the coming elements in discourse whether uttered statements or asked questions. Punctuation has no role in this degree of referential continuity as indicated by AND.

\subsubsection{And as Discontinuity Marker}

Referring to and as a coordinator does not concern all the uses and functions such as independence, equality and reversibility- for which this word is employed. Halliday and Hasan (1976) indicated" Each new sentence is or is not linked to its predecessor, as an independent fact; and if it is and (the additive relation) is one way in which it may be so linked" (P. 235). 
As a discourse marker, BUT has several functions and the most common of them is to highlight the idea that a coming unit has a sense of contrast. So, Schirrfin (1987) indicates

Although the contrastive meaning of BUT gives it a narrower range of than and, its range is still fairly wide for the simple reason that contrastive relationships themselves are knowledge-based and context-based, as well as proposition -based. ( $P$. 176).

Accordingly, but is used " when the content of what is said contrasts with speakers' perceptions about how their talk will be taken as a portrayal of self and when those perceptions clash with their sense of what would constitute a suitable self for presentation to their hearers" (Schiffrin, 1987, P. 158). Gao (2014) comments that " the words which contrast in meaning may not be antonyms because they may be different in their breadth or range of application". (P.235).

One of the most famous roles of BUT is to indicate that a certain unit has a sense of contrast to its proceeded one. As the contrastive relationships are knowledge -based and context -based, the use of BUT is wide. In other words, BUT is used when what is said contradicted with the speakers' realization of what is actually said.

Moreover, disagreement is one of the essential functions of BUT, the efforts of the speaker can be grouped under the 
heading contrastive actions which include interruptions, distraction, challenges and disagreements.

BUT carries or conveys the following sense of repeated referential contrast, functional contrast and contrastive actions. Schiffrin (1987) indicates

The use of But reflects the interactional precedence of making one's own point- when such a point has been interrupted, misunderstood and/or challenged, and when such a point is the object of a speaker commitment ...It should be surprising that BUT is used not only when speakers defend their points against challenges, but when they actually issue those challenges , that is, when they initially disagree. (P.175).

\section{Data Analysis}

\section{1) Deixis}

Temporal Deixis (Now and Then)

As a temporal Deixis, the role of now is to clarify the timing of events not from the view of the narrator, but from the character(s) itself/themselves. Since now refers to the occurrence of events in the present time, it requires an anaphor to clarify the whole matter or issue and the relation between events and characters. 
This point is clear in the monologue in which Samia talks to herself about her experience in the field of cinema and fame and her acquaintance to some journalists such as Youssef Abd El Hamid.

\section{Samia Says:}

"رئيس التحرير الان صحفي مهم، مشهور، كل الناس تعرفه و تتححدث عنه،

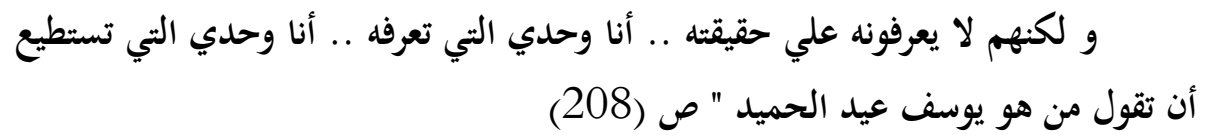

The bitterness in the tone of Samia's speech reflects her terrible experience with Youssef when he was a beginner journalist in "El Ayaam" and the change that occurred to him and to his character.

Ghanem best expressed this change via the use of the temporal deixis Now ; that now refers to New Youssef to become Editor in chief who convinced Samia to marry her but flee in a mission to Syria in their wedding day without informing her .

Being a temporal Deixis , commonly and excessively used by Fathey Ghanem, Then is considered as one of the remarkable features in the novel. Ghanem relies on using Then to express the sequence and following of events, as its excessive use is a substitute for using pauses between sentences. 
As the idea does not end by the end of the sentence, It continues and is includedin one paragraph and sometimes more as It lasts for one or two pages length .

This is clear in the retrieve of Samia to her memories with Marko - The Italian Guy - during their teenth.

\section{Samia says:}

"اعتقل البوليس ماركو لانه ايطالي ، و انجلترا تحارب ايطاليا ، فبكيت مع يونالدا "

The arrest of Marco is followed by the grief and sorrow of Samia or Bahia -at that time- who forgot him, their love affair and every thing and made other relations with other guys and enjoyed her life. Samia says:

\section{"فاخرج معهم و نلهو و نرقص و نغني الاغاني الجديدة " ص (241).}

\section{2) Spatial Deixis (Here and There)}

In the first part of the Quarlet entitled "Mabrouka" , the young girl narrates her journey to the great world-Cairo- and the small world - the house of Rateb Bay. During narration, Ghanem relies on using the spatial deixis There which will let the reader be listener and watcher and evident in the whole novel. In the beginning of the journey, during the discourse between Mabrouka's mother and Othman, the porter of Rateb Bay, he points and states:

$$
\text { "ما تقعدوش قدام الباب خشوا جوه .. }
$$




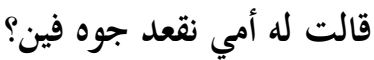 \\ فأشار الي الناحية التي ذهب اليها الشيخ دسوقي وراء البيت و قال: \\ هناك " ص (3). (3)}

The deixis There is an indicator of the porter's willingness to guide Mabrouka and her mother to their natural place in the house with servants and not in the front of it. The implicature or pragmatic effect - refers to the social status of Mabrouka and her mother as indicated by Ghanem.

In the first part of the Quarlet entitled "Mabrouka" , the young girl narrates her journey to the great world-Cairo- and the small world - the house of Rateb Bay. During narration, Ghanem relies on using the spatial deixis There which will let the reader be listener and watcher and evident in the whole novel itself. In the beginning of the journey, during the discourse between Mabrouka's mother and Othman, the porter of Rateb Bay, he points and states:

ما تقعدوش قدام الباب خشوا جوه .. " - (

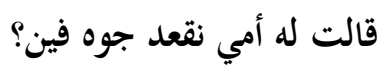

فأشار الي الناحية التي ذهب اليها الشيخ دسوقي وراء البيت و قال:

$$
\text { هناك " ص (3). }
$$

The deixis There is an indicator of the porter's willingness to guide Mabrouka and her mother to their natural 
place in the house with servants and not in the front of it. The implicature or pragmatic effect - refers to the social status of Mabrouka and her mother as indicated by Ghanem.

In the second Part of the Quartet entitled "Samia" who is the narrator of it, Ghanem made use of both Spatial Deixis , Here and There while narrating the relation between Samia and Youssef Abd EL Hamid:

\section{Samia Says:}

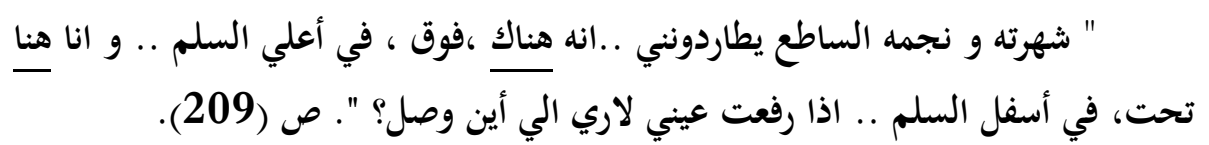

Samia narrates how Youssef betrayed her as he convinced her to neglect the starring of a film and be a house wife after marrying him. In the wedding day, Youssef travelled suddenly to Syria in an important mission which helped him to be a famous journalist. So, such use of the contradicted deixis here and there points to the contradiction between their positions. He becomes a famous journalist, an editor in chief of a a famous journal " El Ayam" or he is in the top of the social ladder while she stays as an non-famous actress or stays in the bottom of this social ladder. The attitude of Youssef stressed the warning of Mohamed Nagy to Samia from him as Nagy indicates that Youssef will leave you in the nearest chance as he searched for his sucess and fame in Syria and leaving her in Egypt after rejecting the starring of a film. 


\section{2) Discourse markers (And \&But)}

$$
\text { تقول مبروكة }
$$

" في تلك اللحضة شعرت بالخوف و لازمني هذا الشعور وِ أنا أهبط من القطار الي

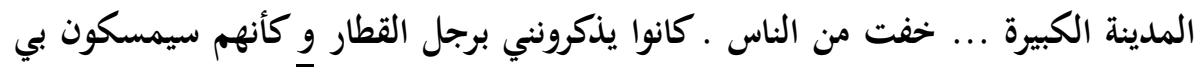
في أية لحظة ،و يسألوني عن عمري. لسبب مجهول لا أعلمه وِ ركبنا الثرام وِ أنا أظن أنه أنه

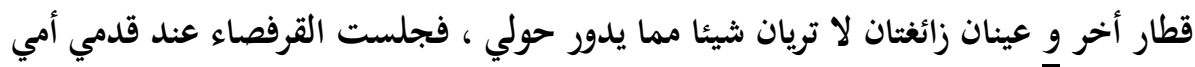

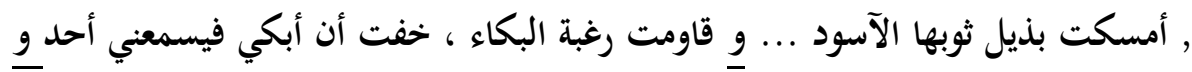

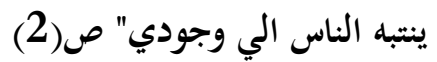

The use of discourse marker (And) by Fathey Ghanem plays an important role in reflecting the feeling of fear and terror of Young Mabrouka in this large city (Cairo). For a whole paragraph which covers more than one page, Ghanem continues his narration without pause or stop of sentences but sentences are linked by and which reflects the continuity of the fear feelings of the young girl which resumes to have the feeling of cry.

Thus, the role of and become effective as it does not link separate units such as words or sentences as it is clear in

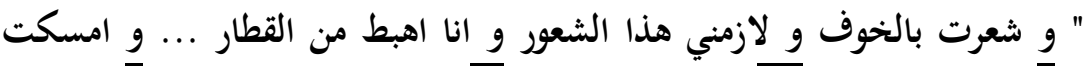

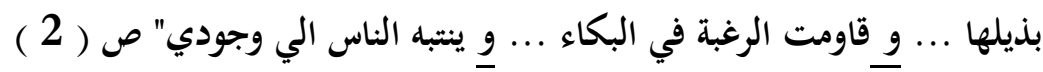

The monologue occurs after her talk to the director Helmy Kamel who would like to drive her home - after her visit to Studio Misr. But, she apologizes that she has an 
appointment. After that, Samia regrets her refusal upon the director's invitation and indicates that if he insists she 'll agree. There comes the role of BUT to indicate the contrast aspect between what she did and what she should do as there is a contrast between her attitude (to leave) and the director's attitude ( to stay for a while ). Then comes the pragmatic effect of BUT, when the director asks her to search for a nick name for her, thus there is a change or oscillation between leaving or staying in the studio and mover to another issue which is searching for a new and a nick name which clarifies the element of contrast.

Samia says:

فشعرت بالندم .. لأني أرتبط بمو عد ، و فكرت في أن أتجاهل مو عدي ، و أتراجع

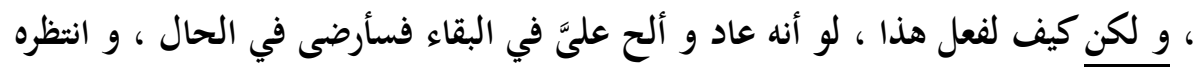

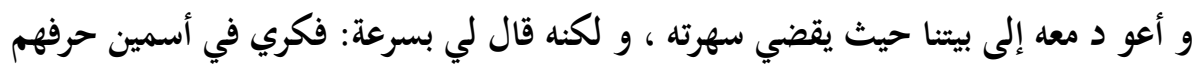

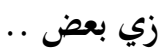

\section{علي العموم هتلاقيني في البيت لما ترجعي " (ص 211).}

The contradiction between Youssef in the past and Youssef today is best expressed by the discourse Marker (DM) BUT . It is clear in the contradiction between two clauses:

Samia says:

$$
\text { "كل الناس تعرفه و لكنهم لا يعرفونه علي حقيقته }
$$


So, the use of BUT has pragmatic effect which is to enhance the difference between the character and behavior of Youssef as described by Samia and that described by other people as Samia is the only one who knows his character, deeds and life style. 


\section{Discussion and Results}

Regarding Ghanem 's profession as a journalists, he tends to be accurate to a great extent. He relies on using discourse markers to keep the fluency of sentences especially as he describes places, events and character's personalities and keep the consciousness of the reader following the whole scene with its specific detail as if he/she (the reader) actually attends and sees it. Ghanem uses only pauses between one sentence and another to indicate the shift from on shot of the scene to another which allows the reader to move with his imagination from one shot to another which is the main function of the pauses between sentences with keeping the element of sequence within the scene. Thus, the speaker uses (and) in his description of events as one action follows the other.

\section{b. Deixis (There)}

The second predominant item - in the contextual aspect - that spreads in both novels is the deixis there. Its function as determiner of the occurrence of events especially in Hemingway's description of nature, sports and place of events. Also, It is helpful for Ghanem within his description of events , actions and movement and reactions of his characters which finally reflect their style of writing and the themes dealt with by both novelists .

\section{References}


Abdel Qader, F. (1999). Playing Cat and Mouse. Al Ahram Weekly (11-17 February). Issue No. (614),18.

Altshuler, D. (2009). Meaning of "now" and other temporal location adverbs. Oxford: Oxford University Press. LNAI 6042, PP. 183-192.

Cruse, D.A. (2000). Meaning in Language. An Introduction to Semantics and Pragmatics. Oxford: Oxford University Press.

Eid, H. (1995). Fathey Ghanem: Life and Creativity. Cairo: EL-Amal Cooperation for Printing and Publishing .

El Sabagh, M.(1995). Diary of Journalists in the Service of Authority. London, Egypt: Dar El Khayal .

EL-Kaeed, Y. (2011). A seminar entitled Fathey Ghanem : A creative Who Does Not Lost his Shadow organized by the cultural committee of the Supreme Council of Culture on 165-2011.

Fraser, B. (1996). Pragmatic Markers. Pragmatics. 6:16780.

Halliday, M.A.K. and Hasan. R. (1976). Cohesion in English. London: Longman.

Laczko, K. (2012). Spatial Deixis and Demonstrative Pronouns in Hungarian. Selected papers from UK-CLA Meetings. Vol. 1, PP. 289-301. 
Schiffrin, D. (1987). Discourse Markers . Cambridge: Cambridge University Press.

Song, L. (2010). The Role of Context in Discourse Analysis. Journal of Language Teaching and Research. Vol. 1, No. 6, PP. 876-879. 